\title{
Comparison between microprocessor-controlled ankle/foot and conventional prosthetic feet during stair negotiation in people with unilateral transtibial amputation
}

\author{
Vibhor Agrawal, PhD; ${ }^{1-2 *}$ Robert S. Gailey, PhD, PT; ${ }^{1-2}$ Ignacio A. Gaunaurd, PhD, MSPT; ${ }^{1-2}$ Christopher \\ O’Toole, MS; ${ }^{2}$ Adam A. Finnieston, CPO, LPO $^{2-3}$ \\ ${ }^{1}$ Department of Physical Therapy, Miller School of Medicine, University of Miami, Coral Gables, FL; ${ }^{2}$ Functional \\ Outcomes Research and Evaluation Center, Miami Department of Veterans Affairs Medical Center, Miami, FL; ${ }^{3}$ Arthur \\ Finnieston Prosthetics + Orthotics, Miami, FL
}

\begin{abstract}
Contrary to stance-phase dorsiflexion of conventional prosthetic feet, the microprocessor-controlled Proprio foot permits swing-phase dorsiflexion on stairs. The purpose of this study was to compare Symmetry in External Work (SEW) between a microprocessor-controlled foot and conventional prosthetic feet in two groups with unilateral transtibial amputation (Medicare Functional Classification Levels K-Level-2 and K-Level-3) during stair ascent and descent. Ten subjects were evaluated while wearing three conventional prosthetic feetsolid ankle cushion heel (SACH), stationary attachment flexible endoskeleton (SAFE), and Talux - and the Proprio foot using a study socket and were given a 10- to 14-day accommodation period with each foot. Ground reaction forces were collected using F-scan sensors during stair ascent and descent. The SEW between the intact and amputated limbs was calculated for each foot. During stair ascent, the Proprio foot resulted in a higher interlimb symmetry than conventional prosthetic feet, with significant differences between the Proprio and SACH/SAFE feet. The swing-phase dorsiflexion appeared to promote greater interlimb symmetry because it facilitated forward motion of the body, resulting in a heel-totoe center of pressure trajectory. During stair descent, all feet had low symmetry without significant differences between feet. The movement strategy used when descending stairs, which is to roll over the edge of a step, had a greater influence on symmetry than the dorsiflexion features of prosthetic feet.
\end{abstract}

Key words: center of pressure, external work, foot dorsiflexion, microprocessor-controlled foot, Proprio foot, prosthetic feet comparison, stair ascent, stair descent, symmetry, Symmetry in External Work.
Abbreviations: $\mathrm{AMP}=$ Amputee Mobility Predictor, $\mathrm{COM}=$ center of mass, $\mathrm{COP}=$ center of pressure, DMERC $=$ Durable Medical Equipment Regional Carrier, DR = dynamic response, GRF $=$ ground reaction force, ICC $=$ intraclass correlation coefficient, MFCL = Medicare Functional Classification Level, PVD = peripheral vascular disease, $\mathrm{SACH}=$ solid ankle cushion heel, SAFE = stationary attachment flexible endoskeleton, $\mathrm{SD}=$ standard deviation, SEW = Symmetry in External Work, TTA = transtibial amputation, VA = Department of Veterans Affairs.

*Address all correspondence to Vibhor Agrawal, PhD; Department of Physical Therapy, Miller School of Medicine, University of Miami, 5915 Ponce de Leon Blvd, Plummer Building 5th floor, Coral Gables, FL 33146; 305-2844535; fax: 305-575-3248.

Email: vibhor@umail.miami.edu http://dx.doi.org/10.1682/JRRD.2012.05.0093 


\section{INTRODUCTION}

The kinematics and kinetics of lower-limb joints during stair ambulation are different from those during level walking [1]. The majority of prosthetic feet are designed with an emphasis on level-ground gait and do not consider the biomechanics of functional activities such as ascending and descending stairs. While the physiological ankle can actively dorsiflex up to $27^{\circ}$ during movement on stairs [1-2], prosthetic feet with solid ankle designs are fixed at $90^{\circ}$ and those with articulated ankles and Jshaped ankle springs vary the amount of functional dorsiflexion based on their design. The Proprio foot (Össur Inc; Reykjavik, Iceland) consists of a microprocessorcontrolled ankle that can dorsiflex up to $4^{\circ}$ during stair ascent and descent. Alimusaj et al. recently reported that the active dorsiflexion of the Proprio foot/ankle during the swing phase of stair negotiation improved knee kinematics and kinetics compared with a fixed ankle that allowed no active motion [3]. However, it is unknown whether the swing-phase dorsiflexion feature of the Proprio foot offers any advantage to users with unilateral transtibial amputation (TTA) over conventional prosthetic feet with varying degrees of stance-phase dorsiflexion during stair ascent and descent.

Few studies comparing the effects of prosthetic feet on stair mobility have been published. Torburn et al. calculated the stride characteristics of 10 subjects with traumatic amputation using five prosthetic feet during stair ascent and descent [4]. The stride characteristics were calculated by means of foot switches as subjects ascended and descended a 4-step portable staircase. During ascent, the Flex Foot (Össur Inc) and Carbon Copy Foot (The Ohio Willow Wood Co; Mt. Sterling, Ohio) resulted in a more symmetrical gait (ratio: 1.03 and 1.05, respectively) only during the initial double-limb support phase and were significantly different than the solid ankle cushion heel (SACH) foot (ratio: 1.3). During stair descent, no significant differences in stride characteristics were found among prosthetic feet. Torburn et al. concluded that none of the five test feet was clinically more advantageous for stair ambulation. Yack et al. studied the lower-limb joint moments and powers during stair ascent with three different prosthetic feet [5]. They concluded that subjects with amputation use a hip-extensor dominant strategy on the amputated side during stair ascent, and dynamic response (DR) feet (Flex Foot and Re-Flex VSP [Össur Inc]) are advantageous over a SACH foot because they reduce the moments and power generation at the hip joint. The only study using a microprocessorcontrolled foot for stair negotiation was published by Alimusaj et al., who tested the Proprio foot with its active dorsiflexion feature, the "stair mode," turned on and turned off [3]. They reported a significant change in the hip and knee moments between the two conditions for both stair ascent and descent. They concluded that the active dorsiflexion feature improves the knee kinetics and kinematics on the amputated side during stair ambulation. While comparisons between DR and non-DR feet have been reported, no studies have investigated the differences in stair ambulation between a microprocessorcontrolled foot and conventional prosthetic feet in those with TTA at two distinct functional levels.

In the United States, the Medicare Functional Classification Level (MFCL) classifies mobility of people with lower-limb loss into five functional levels, primarily based on their potential to ambulate with a prosthesis (Table 1) [6-7]. Subsequent to recommendations by manufacturer representatives and invited advisors, the Centers for Medicare and Medicaid Services committee assigned prosthetic feet to a specific MFCL K-Level (categories K1-K4 feet) based on their mechanical properties (Table 1). In the majority of cases, a person with amputation's functional classification dictates the respective category of prosthetic foot prescribed and worn.

Because of the variability in functional dorsiflexion characteristics of prosthetic feet, those with unilateral TTA may employ altered strategies to ascend and descend stairs with different prosthetic feet. Schmalz et al. have demonstrated higher forces through the intact limb joints and asymmetrical movement between limbs with a 1D25 prosthetic foot (Otto Bock; Duderstadt, Germany) and concluded that concurrent prosthetic feet did not provide sufficient dorsiflexion-plantar flexion during stair negotiation [8]. Currently, there is little evidence to conclusively determine the potential adversities in TTA associated with stair ambulation, such as falls, increased forces on the intact limb, or kinetic asymmetry leading to degenerative joint disease. While the negative effects of asymmetry have never been documented in this population, there are concerns about the long-term clinical risks. For example, people with lower-limb amputation have a significantly higher prevalence of degenerative joint diseases in the contralateral knee and lower back pain [9]. While a causal relationship to asymmetries has never been well established, the inference that a relationship may exist has been described previously in the literature 
Table 1.

Medicare Region C Durable Medical Equipment Regional Carrier prosthetic policy definition of foot/ankle assemblies and knee units by Medicare Functional Classification Level (MFCL) [6].

\begin{tabular}{|c|c|c|c|}
\hline $\begin{array}{l}\text { MFCL } \\
\text { Level }\end{array}$ & Description & $\begin{array}{l}\text { MFCL } \\
\text { Modifier }\end{array}$ & Foot/Ankle Assembly \\
\hline$\overline{0}$ & $\begin{array}{l}\text { Does not have ability or potential to ambulate or transfer safely with or with- } \\
\text { out assistance, and prosthesis does not enhance quality of life or mobility. }\end{array}$ & K0 & Not eligible for prosthesis. \\
\hline 1 & $\begin{array}{l}\text { Has ability or potential to use prosthesis for transfers or ambulation in level } \\
\text { surfaces at fixed cadence. Typical of limited and unlimited household } \\
\text { ambulator. }\end{array}$ & K1 & $\begin{array}{l}\text { External keel, solid ankle cushion } \\
\text { heel foot, or single-axis ankle/foot. }\end{array}$ \\
\hline 2 & $\begin{array}{l}\text { Has ability or potential for ambulation with ability to traverse low-level } \\
\text { environmental barriers such as curbs, stairs, or uneven surfaces. Typical } \\
\text { of limited community ambulator. }\end{array}$ & K2 & $\begin{array}{l}\text { Flexible-keel foot or multiaxial } \\
\text { ankle/foot. }\end{array}$ \\
\hline 3 & $\begin{array}{l}\text { Has ability or potential for ambulation with variable cadence. Typical of } \\
\text { community ambulator who has ability to traverse most environmental } \\
\text { barriers and may have vocational, therapeutic, or exercise activity that } \\
\text { demands prosthetic utilization beyond simple locomotion. }\end{array}$ & K3 & $\begin{array}{l}\text { Flex Foot system, energy-storing } \\
\text { foot, multiaxial ankle/foot, } \\
\text { dynamic response, or flex-walk } \\
\text { system or equal. }\end{array}$ \\
\hline 4 & $\begin{array}{l}\text { Has ability or potential for prosthetic ambulation that exceeds basic ambu- } \\
\text { lation skills, exhibiting high impact, stress, or energy levels. Typical of } \\
\text { prosthetic demands of child, active adult, or athlete. }\end{array}$ & K4 & Any ankle/foot system appropriate. \\
\hline
\end{tabular}

[10]. If asymmetry is a contributor to reduced functional mobility, decreased balance, and the risk of degenerative joint disease related to overuse, then the goal of achieving symmetry may have a distinct clinical value.

Symmetry in External Work (SEW) is a biomechanical measure that can detect interlimb kinetic asymmetry during stair ascent and descent [11]. In this measure, external work done by the intact and prosthetic limbs is calculated by integrating ground reaction forces (GRFs) and center of mass (COM) displacement over a step [12]. This measure has the potential to be made clinically friendly because it can assess amputation gait kinetics with minimal resources and in the everyday environment. During level walking, the SEW measure has been shown to successfully differentiate gait asymmetry between prosthetic feet having diverse designs and functional properties [12]. The purpose of this study was to compare the effect of functional prosthetic ankle dorsiflexion on SEW values between a microprocessor-controlled foot and three conventional prosthetic feet in two groups with unilateral TTA (MFCL K-Level-2 and K-Level-3) as they ascended and descended a staircase with 11 steps.

\section{METHODS}

Subjects with unilateral TTA were eligible to participate in the study if they met the following inclusion criteria: male or female; aged between 40 and $65 \mathrm{yr}$; comfortably fit with a prosthesis for a minimum of 6 mo; unilateral lowerlimb amputation secondary to peripheral vascular disease (PVD), traumatic event, or tumor; could ambulate with prosthesis on level surface with a consistent cadence for a minimum of $200 \mathrm{~m}$; could safely negotiate stairs; and could tolerate all study procedures. Individuals were excluded from study participation if they currently weighed more than $115 \mathrm{~kg}$ (255 lb); had contractures at the hip, knee, or ankle joints; presented with wound or partial foot amputation on the contralateral intact limb; presented with a poorly fit prosthesis; presented with open wound or blisters to the residual limb; had poor control of diabetes mellitus and/or severe neuropathy of the intact foot as determined by a Semmes-Weinstein monofilament; or presented with arthritis and/or cardiopulmonary disease limiting their ability to perform study activities and standardized functional prosthetic gait training.

Informed written consent was obtained from all subjects prior to study participation. The study physician assessed current and past medical conditions of each subject, including foot examination, neuropathic assessment, vascular assessment, and foot ulceration history. A prosthetist inspected the subjects' residual limbs for any limitations that would cause pain, prohibit prosthetic wear, or put subjects at risk throughout the course of the study. Subjects started the experimental procedure only after receiving clearance by the study physician and prosthetist. 
The test-retest reliability of the measurement instrument (F-scan sensors) during stair negotiation was determined by testing five subjects with unilateral TTA (Table 2) twice over a 48 to $72 \mathrm{~h}$ period, and SEW was determined for each session. The mean \pm standard deviation (SD) age and time since amputation for these subjects was $54 \pm 7.1 \mathrm{yr}$ and $3.4 \pm$ 1.8 yr, respectively. Vertical GRFs were collected with the F-scan sensors as subjects ascended and descended an 11step test staircase with a step height of $17 \mathrm{~cm}$ and step tread of $28.5 \mathrm{~cm}$. Subjects wore standardized shoes and socks throughout the testing procedure, and data collection with Fscan sensors was performed using previously validated procedures [13-14]. The SEW values for stair ascent and descent were computed using the equation described later. Three representative strides obtained after the fourth step were used to calculate a mean SEW value between limbs, and the intraclass correlation coefficient (ICC) between test and retest sessions was determined. For both the ascending and descending activities, ICC was found to be 0.84 , which is similar to the reliability of F-scan sensors published during level walking.

To compare the microprocessor-controlled foot with conventional prosthetic feet, a sample of 10 individuals with TTA were enrolled (Table 3). Five subjects had an amputation because of PVD and five had an amputation caused by either trauma or tumor. Subjects were classified as MFCL K-Level-2 or K-Level-3 based on a mean \pm SD Amputee Mobility Predictor (AMP) score of $37.0 \pm 2.0$ and $43.2 \pm 1.3$, respectively [7]. The K-Level-2 subjects had a mean \pm SD age of $60.6 \pm 2.1 \mathrm{yr}$ and time since amputation of $3.0 \pm 1.5 \mathrm{yr}$, while the K-Level-3 subjects had a mean \pm SD age of $51.0 \pm 5.8 \mathrm{yr}$ and time since amputation of $16.0 \pm 17.5$ yr. The K-Level-2 and KLevel-3 subject groups were significantly different in terms of their mean age and AMP scores.

Table 2.

Demographic characteristics of 5 test subjects used to determine testretest reliability of F-scan sensors during stair negotiation.

\begin{tabular}{lcccc}
\hline $\begin{array}{l}\text { Age } \\
\text { (yr) }\end{array}$ & Sex & $\begin{array}{c}\text { Side of } \\
\text { Amputation }\end{array}$ & $\begin{array}{c}\text { Cause of } \\
\text { Amputation }\end{array}$ & $\begin{array}{c}\text { Time Since } \\
\text { Amputation* } \\
\text { (yr) }\end{array}$ \\
\hline 64 & M & L & PVD & 3 \\
55 & F & R & Trauma & 7 \\
45 & F & L & Trauma & 3 \\
59 & M & R & PVD & 2 \\
47 & M & R & Tumor & 2 \\
"Numbers have been rounded to nearest whole number. \\
F = female, L = left, M = male, PVD = peripheral vascular disease, R = right. \\
\hline \hline
\end{tabular}

Each subject received a study socket fabricated using a computer-aided design image (BioSculptor software, Maramed Inc; Miramar, Florida) of the subject's residual limb that was modified by the study prosthetist to ensure optimal fit. A suction suspension mechanism with either an Iceross Seal-in liner (Össur Inc) or a cushion liner and external sleeve was used for all subjects. Each participant tested four prosthetic feet: SACH, stationary attachment flexible endoskeleton (SAFE), Talux feet (conventional prosthetic feet), and Proprio foot (microprocessorcontrolled foot). Subjects received standardized functional prosthetic gait training with their existing socket and foot as well as with the study socket and test feet. For stair ascent, subjects were instructed to place the foot on a step, exert a downward force while extending the hip and knee to raise the body, and place the contralateral limb on the next step in a controlled manner. All subjects were able to ascend and descend the stairs leg-over-leg and were instructed to hold onto the handrail for safety and not as a means to assist with the maneuver. Cues were given to assist with the maneuver when necessary, such as "place as much of the foot on the step as possible," "keep the trunk flexed forward and keep the movement continuous,” and “don't hesitate.”

Stair decent training varied slightly with the type of foot. The SACH and SAFE feet have rigid ankles that limit the dorsiflexion that occurs as the stance-limb knee flexes to lower the body to a subsequent step. Therefore, the technique selected to accommodate for the absence of

Table 3.

Demographic characteristics of study subjects.

\begin{tabular}{lcccccc}
\hline $\begin{array}{l}\text { MFCL } \\
\text { Class }\end{array}$ & $\begin{array}{c}\text { Age }^{*} \\
\text { (yr) }\end{array}$ & Sex & $\begin{array}{c}\text { Side of } \\
\text { Amputation }\end{array}$ & $\begin{array}{c}\text { Cause of } \\
\text { Amputation }\end{array}$ & $\begin{array}{c}\text { Time Since } \\
\text { Amputation } \\
\text { (yr) }\end{array}$ & $\begin{array}{c}\text { AMP } \\
\text { Score at } \\
\text { Baseline }\end{array}$ \\
\hline K-Level-2 & 59 & M & R & PVD & 2 & 37 \\
K-Level-2 & 64 & M & L & PVD & 3 & 39 \\
K-Level-2 & 61 & M & R & PVD & 6 & 39 \\
K-Level-2 & 58 & M & L & PVD & 2 & 35 \\
K-Level-2 & 61 & M & L & PVD & 2 & 35 \\
K-Level-3 & 47 & M & R & Tumor & 2 & 44 \\
K-Level-3 & 55 & F & R & Trauma & 7 & 42 \\
K-Level-3 & 43 & M & R & Trauma & 1 & 45 \\
K-Level-3 & 53 & M & L & Trauma & 33 & 43 \\
K-Level-3 & 57 & M & L & Trauma & 37 & 42 \\
\hline
\end{tabular}

${ }^{*}$ Numbers have been rounded to nearest whole number.

$\mathrm{AMP}=$ Amputee Mobility Predictor, $\mathrm{F}=$ female, $\mathrm{L}=$ left, $\mathrm{M}=$ male, $\mathrm{MFCL}=$ Medicare Functional Classification Level, PVD = peripheral vascular disease, $\mathrm{R}=$ right. 
ankle dorsiflexion required that approximately one-half of the prosthetic foot extend over the step so that prosthetic foot could "roll-over" the edge of the step, permitting a smooth transition as the contralateral limb descends to the next step. The J-shaped pylon of the Talux foot allows relatively greater dorsiflexion, and as a result, subjects were trained to place more of the prosthetic foot on the step. With the active dorsiflexion feature of the microprocessor-controlled foot, subjects were trained to retain a greater portion of the prosthetic foot on the step while achieving a smooth transition to the next lower step.

The objective of standardized training with a subject's existing socket and foot was to minimize deviations resulting from habit or lack of training, while the objective of training with each test foot was to enable the subject to maximize use of the mechanical properties of each foot during stair negotiation. At each training session, a subject's movement proficiency was assessed on predefined criteria, which included rating on a 4-point ordinal scale: (1) unable (to perform the activity), (2) minimal level, (3) with difficulty, and (4) without difficulty. Subjects were trained only in areas in which training was needed, and training was concluded when they satisfactorily performed the activities without difficulty. All training sessions were standardized and administered by the same physical therapist that specialized in the treatment of those with lower-limb amputation.

Comparison between the test feet involved six testing sessions, during which GRF data were collected using the previously mentioned procedure. At the baseline testing session (session 1), subjects used their existing prostheses to perform the stair ascent and descent activities. Following session 1 , they received up to $4 \mathrm{~h}$ of specialized training over a 2 wk period. In session 2 (training session), the effect of prosthetic training on movement biomechanics was assessed in the subject's existing socket and foot. Subsequently, subjects were fit with the study socket and a randomly selected prosthetic foot. During the 10 to $14 \mathrm{~d}$ accommodation period with this foot, subjects received at least $1 \mathrm{~h}$ and up to $4 \mathrm{~h}$ of training to maximize the use of this foot. The accommodation period was determined based on clinical judgment because the time required for those with unilateral TTA to accommodate to a prosthesis has not been published in the literature. A 2 wk period was deemed suitable for subjects who were greater than 6 mo postamputation, stable medically, and had undergone adequate training. Session 3 thus measured the effects of the first prosthetic foot on a subject's movement biomechanics. At the end of session 3, subjects were fit with the second randomized test foot and were given appropriate training in the 10 to $14 \mathrm{~d}$ accommodation period. During session 4, effects of the second test foot were measured. The third and fourth feet were tested using the same training and testing procedures.

Work done by the vertical GRF and the resulting COM displacement was calculated using a line integral as described by Agrawal et al. [12]. Symmetry index (SEW value, expressed in percentage) between the intact and prosthetic limbs was calculated using the following equation (Equation (1)):

$$
S E W=100-100 \times\left(\frac{W_{1}-W_{P}}{W_{1}+W_{P}}\right),
$$

where $W_{1}=$ work done by intact limb (in joules) and $W_{P}=$ work done by prosthetic limb (in joules).

A SEW value of 100 percent indicates equal work by each limb, a value greater than 100 percent indicates more work by the prosthetic limb, and a value less than 100 percent indicates more work by the intact limb. A repeated-measures analysis of variance was used to determine differences in symmetry indices between sessions and a significance level of $p<0.05$ was adopted.

\section{RESULTS}

Table 4 shows the mean \pm SD SEW values during stair ascent and descent for both subject groups at the six testing sessions. Table 5 presents the mean difference in SEW values between the microprocessor-controlled foot and conventional prosthetic feet. For both subject groups, standardized training did not result in a significant change in work symmetry during ascending or descending stairs. During stair ascent, the Proprio foot exhibited greater interlimb symmetry than the SACH and SAFE feet in both subject groups. The Proprio foot also resulted in a higher mean symmetry value than the Talux foot in both groups during stair ascent; however, the differences between feet were not statistically significant. While descending stairs, all the test feet yielded low symmetry indices, indicating a higher dependence on the intact foot during this activity. 
JRRD, Volume 50, Number 7, 2013

Table 4.

Mean \pm standard deviation Symmetry in External Work (SEW) value of K-Level-2 and K-Level-3 subjects with amputation while ascending and descending 11-step staircase.

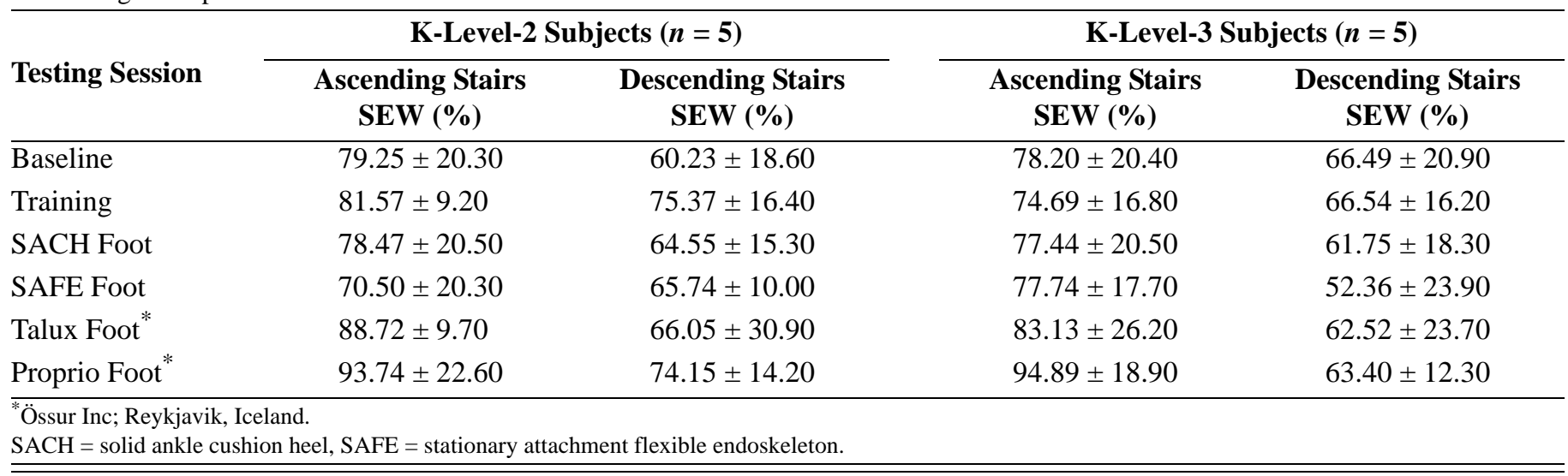

Table 5.

Mean difference in Symmetry in External Work (SEW) values between microprocessor-controlled foot and conventional prosthetic feet while ascending and descending stairs.

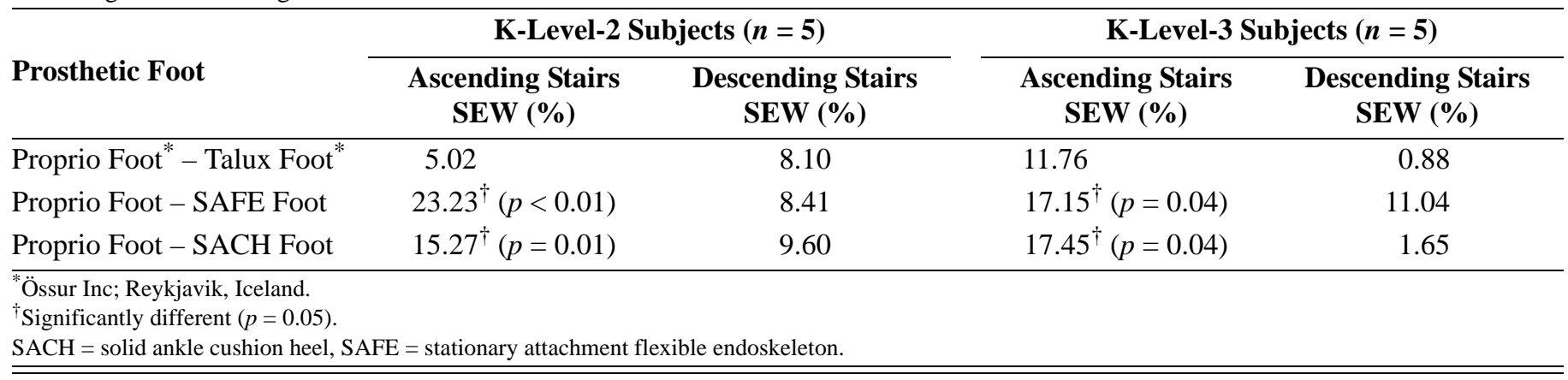

\section{DISCUSSION}

The number of research studies investigating amputation gait on stairs is limited, with only one article published with the microprocessor-controlled foot [3]. Torburn et al. concluded that the gait of subjects with TTA on stairs is different from nonamputation gait, primarily because those with amputation prefer to spend more time on the intact limb [4]. The asymmetrical SEW values obtained in our study, during the majority of stair ascent sessions and particularly during stair descent, corroborate the conclusion made by Torburn et al. [4]. Contrary to conventional feet, the microprocessor-controlled foot resulted in significantly greater SEW values between the lower limbs during stair ascent. However, during stair descent, the interlimb symmetry with the Proprio foot was not significantly better than conventional prosthetic feet. Since the DR characteristics of prosthetic feet have not been shown to be advantageous while negotiating stairs, the swing-phase dorsiflexion of the microprocessor-controlled foot seems to promote kinetic symmetry between the lower limbs while ascending stairs [4].

The study protocol was designed to minimize the influence of confounding variables on amputation gait. The standardized functional prosthetic gait training given to subjects between sessions 1 (baseline) and 2 (training) was intended to reduce deviations, resulting from habit or lack of training, while negotiating stairs. Prosthetic training with each test foot ensured that subjects could maximize the use of functional properties of each foot. The four test feet were selected to represent each MFCL category:

1. K1: SACH foot, identified by name in the Durable Medical Equipment Regional Carrier (DMERC) prosthetic policy definition of foot/ankle assemblies [6].

2. K2: SAFE foot, a truly flexible keel foot. 
3. K3: Talux foot, a Flex Foot with J-shaped DR design (also named in DMERC) combined with multiaxial capabilities because of the elastomer block ankle.

4. K3: Proprio Foot, microprocessor-controlled ankle that provides active dorsiflexion during swing.

By classifying the subjects in K-Level-2 and K-Level-3 groups, we ensured that factors related to age or functional level did not confound the results. The differences in gait symmetry found between prosthetic feet could therefore be attributed only to the design differences between the categories of prosthetic feet.

\section{Ascending Stairs}

Alimusaj et al. investigated the biomechanics of stair ascent using the Proprio foot with its dorsiflexion feature turned on and turned off [3]. They concluded that the dorsiflexion feature of the Proprio foot improves knee kinematics and kinetics of the prosthetic limb. Results of this study provide evidence that the microprocessor-controlled ankle results in greater work symmetry than conventional prosthetic feet. The higher SEW values can be attributed, in part, to a greater symmetry in vertical GRFs between the intact and prosthetic limbs. Typically, during bipedal stair ascent the GRF curve is similar to the M-shaped curve seen in level walking, with a minor difference in magnitude of the first peak [15-16]. However, in those with TTA using conventional prosthetic feet, the first vertical GRF peak with the intact limb was found to be significantly greater than the prosthetic limb [8]. The higher magnitude of GRFs can be attributed to the subject falling off the prosthetic foot on to the intact limb, thus resulting in greater than normal impact forces [8]. The premise of falling on to the intact limb is supported by Torburn et al., who reported an early initial contact of the intact limb and a shortened single-limb support time on the prosthetic limb with conventional prosthetic feet [4]. In subjects without amputation, active ankle dorsiflexion and plantar flexion results in a knee dominant strategy [5], which ensures forward and upward displacement of body COM. In the absence of active ankle dorsiflexion/plantar flexion with conventional prosthetic feet, those with TTA ensure a sufficient vertical position of the COM by employing a hip-extensor dominant strategy with the prosthetic limb $[5,8]$. The hip-dominant strategy with the prosthetic limb and asymmetrical stance times between the limbs are potential factors that also contributed to lower SEW values with conventional prosthetic feet. The microprocessor-controlled foot has been shown to improve hip and knee kinematics [3] and possibly promotes similar stance times with both limbs, resulting in higher SEW values.

The ability of a prosthetic foot to dorsiflex during stance or swing phase and hence allow forward movement of COM appears to be a major contributor to interlimb kinetic symmetry. While the SEW values for the SACH and SAFE feet were comparable, the Talux foot resulted in a relatively higher symmetry. The Figure provides sample images from the F-scan sensors from identical stance periods during stair ascent. These composite images are generated automatically by the F-scan sensor software at the conclusion of each trial by combining multiple frames throughout stance and creating the center of pressure (COP) trajectory. The SACH and SAFE feet have nonarticulated ankles that permit very limited dorsiflexion during the stance phase and thus limit the forward motion of the body over the foot. Conversely, the Talux foot's J-shaped ankle spring design imparts flexibility to its ankle, which allows relatively greater dorsiflexion [17] and thus easier forward movement of body COM over the prosthetic and intact forefoot. The $4^{\circ}$ of active dorsiflexion with the Proprio foot used in this study facilitated the forward motion of the COM, resulting in a COP trajectory comparable with that of the intact foot. The degree of dorsiflexion for each prosthetic foot can vary depending on the predetermined foot and/or socket alignment, as determined by the prosthetist. The effects of different prosthetic alignment configurations between feet have not been described in the literature but may influence stair ascent and descent symmetry.

There may be two benefits to the active dorsiflexion of the Proprio foot during the swing phase of stair ascent. First, as the foot lands in a preset dorsiflexed position, it permits unimpeded forward continuation of the body COM over the stance limb, which results in a heel-to-toe COP trajectory. Second, improved kinematics from the increased dorsiflexion and resultant knee flexion [3] potentially facilitates improved muscular effort of the stance limb to maintain the upward and forward momentum of body COM as it proceeds to the next step. Conversely, in conventional prosthetic feet and J-shaped foot designs, the foot lands flat on the step with the ankle at a neutral $90^{\circ}$ angle ( $0^{\circ}$ dorsiflexion). This requires the subject to either slow the COM progression until enough body weight is over the ankle to promote dorsiflexion or to adopt a different strategy, such as ascending stairs with initial contact at the midfoot or forefoot (toe walking). 
(a)

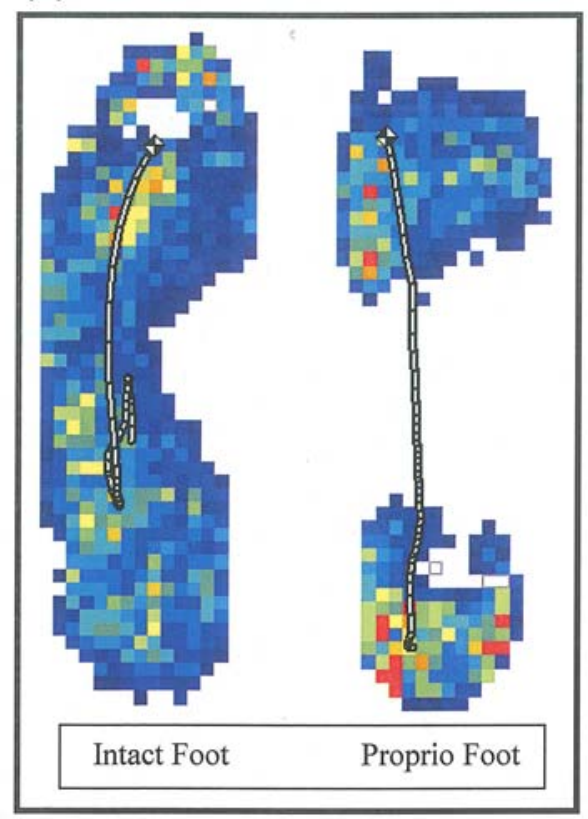

(c)

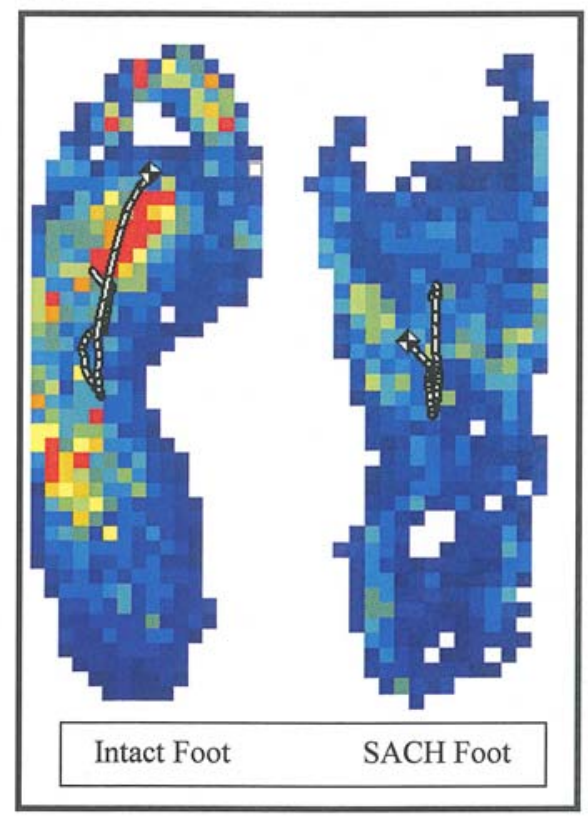

(b)

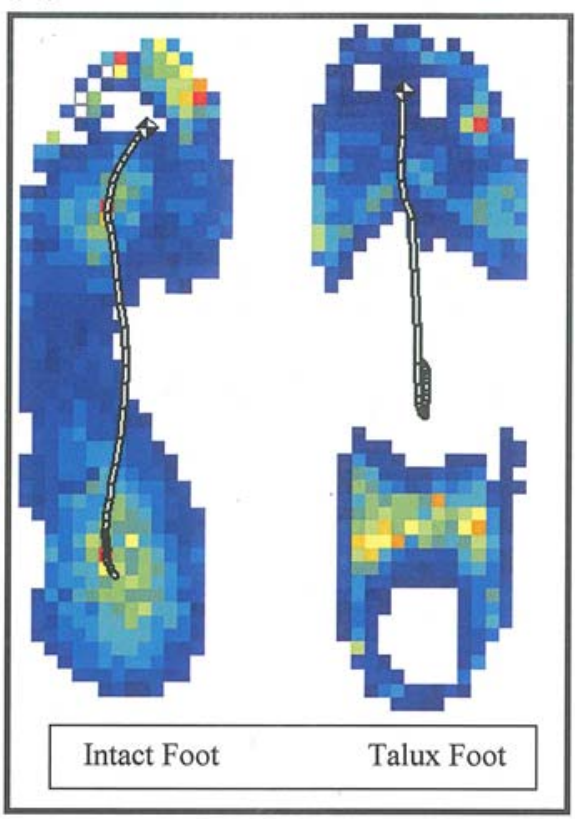

(d)

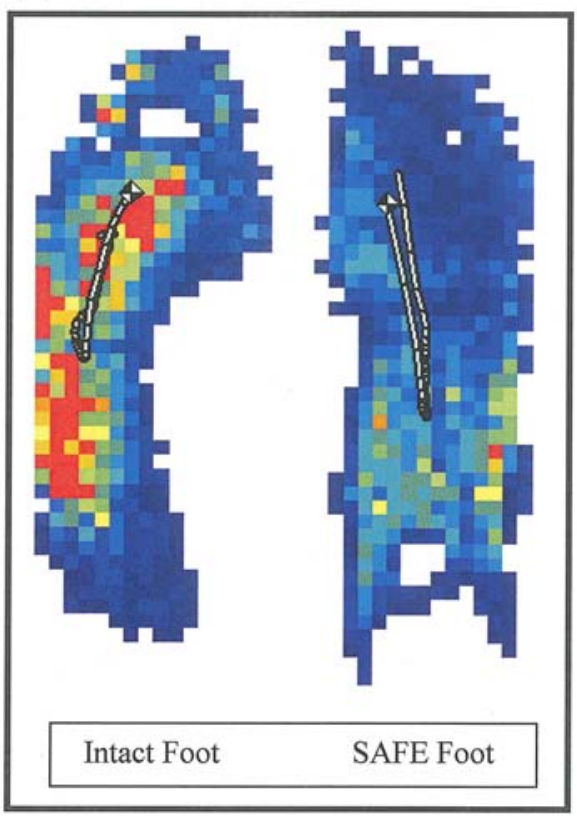

Figure.

Comparison of center of pressure trajectory between test feet for one study participant. (a) Intact foot and Proprio foot (Össur Inc; Reykjavik, Iceland), (b) intact foot and Talux foot (Össur Inc), (c) intact foot and solid ankle cushion heel (SACH) foot, and (d) intact foot and stationary attachment flexible endoskeleton (SAFE) foot.

\section{Descending Stairs}

During stair descent, the SEW values were quite similar among the prosthetic feet, with consistently low sym- metry indices. A similar result was presented by Torburn et al. in a comparison of five prosthetic feet [4]. They concluded that none of the feet improved symmetry during 
stair descent. While descending, the peak vertical GRF on the intact limb can reach up to 1.5 times body weight compared with the prosthetic limb, where the peak vertical GRF is approximately equal to the body weight [8]. None of the test feet resulted in a significant change in the vertical GRFs or stance times between limbs or the strategies used for stair descent.

Contrary to the results of our study, Alimusaj et al. reported significant differences in knee kinematics and kinetics while descending stairs [3]. The differences can be attributed to the strategy used by those with TTA while descending stairs. Because of a lack of active dorsiflexion at the prosthetic ankle of conventional feet, subjects were trained to place the midfoot on the edge of the step while continuing to roll over the step. While this method of descending stairs may not be the most efficient, it represents the best strategy for those with amputation to successfully execute this activity. With the Proprio foot, the training was modified to accommodate the dorsiflexion feature of the ankle during stair descent. The similar SEW values suggest that regardless of the specialized Proprio training, subjects returned to adopting the same strategy of rolling over the edge of the step even with the Proprio foot.

Several limitations were identified in this study. The altered strategies employed by the subjects while descending stairs suggest the possibility of work calculation limitations only for this task because of the shortcomings of current in-sole sensor technology. Since the F-scan sensors are capable of measuring only the normal forces applied to the sensor, movement of the prosthetic foot over the edge of the step may have resulted in GRFs having a substantial shear component. The SEW results during stair descent should therefore be interpreted and weighed appropriately. This strategy of rolling over the edge of the step during stair descent presents a significant challenge in the measurement of GRFs with commercially available instrumentation. However, with some error, the SEW measure was able to quantify the asymmetry that was apparent during stair descent. An advantage of determining interlimb symmetry with measures like the SEW - as opposed to comparing movement kinetics in subjects without amputation-is the ability to quantify similarity in strategies used by the intact and prosthetic limbs to move the body during the stair negotiation. The absence of motion-capture data restricted our ability to determine the joint kinematics, which limited the discussion to clinical observation and findings published in the literature. All prosthetic fitting and alignment procedures were performed by the same board-certified prosthetist using standard protocols as stated in the manufacturer's technical manual. At the time of data collection, there were no commercially available, reliable, and valid devices that could quantify dynamic alignment of a prosthetic foot.

\section{CONCLUSIONS}

During stair ascent with unilateral TTA, the microprocessor-controlled Proprio foot resulted in greater interlimb work symmetry than conventional prosthetic feet. Prosthetic feet that can facilitate forward COM movement, by dorsiflexing at the ankle either during the stance or swing phase of stair ascent, have the potential to promote work symmetry between limbs. During stair descent, the strategy of rolling over the edge of the step with the prosthetic foot resulted in an asymmetrical movement pattern, which was similar between the microprocessor-controlled foot and conventional prosthetic feet. Therefore, individuals with unilateral TTA who function at either K-Level-2 or K-Level-3 and have to negotiate stairs on a regular basis, within their home, community, or work environment, may benefit from the use of the Proprio foot or other microprocessor-controlled feet that allow active dorsiflexion during swing.

\section{ACKNOWLEDGMENTS}

\section{Author Contributions:}

Study concept and design: V. Agrawal, R. S. Gailey. Acquisition of data: V. Agrawal, C. O’Toole, I. A. Gaunaurd, A. A. Finnieston.

Analysis and interpretation of data: V. Agrawal, C. O’Toole, R. S. Gailey. Drafting of manuscript: V. Agrawal.

Critical revision of manuscript for important intellectual content:

V. Agrawal, R. S. Gailey, C. O’Toole, I. A. Gaunaurd, A. A. Finnieston. Statistical analysis: V. Agrawal.

Study supervision: V. Agrawal, I. A. Gaunaurd.

Financial Disclosures: Össur Americas provided financial and technical support for this study. The standard Cooperative Research and Development Agreement between the Miami Department of Veterans Affairs (VA) Healthcare System, Össur Americas, and the South Florida Veterans Affairs Foundation for Research and Education was executed and observed throughout the research process. Dr. Gailey is an education consultant with Össur Americas.

Funding/Support: This material was based on work supported with the resources and the use of facilities at the Miami VA Medical Center. Additional Contributions: The authors would like to thank Össur Americas for their support of this research study and providing technical assistance with the microprocessor-controlled Proprio foot; the South 
Florida Veterans Affairs Foundation for Research and Education (Miami, Florida) for administering the research project; and all the study participants for their time and dedication. Mr. O’Toole is now with the Miami Project to Cure Paralysis.

Institutional Review: This study was approved by the Institutional Review Board and Human Studies Subcommittee at the Miami VA Healthcare System.

Participant Follow-up: The authors plan to inform participants of the publication of this study.

\section{REFERENCES}

1. Andriacchi TP, Andersson GB, Fermier RW, Stern D, Galante JO. A study of lower-limb mechanics during stair-climbing. J Bone Joint Surg Am. 1980;62(5):749-57. [PMID:7391098]

2. McFadyen BJ, Winter DA. An integrated biomechanical analysis of normal stair ascent and descent. J Biomech. 1988;21(9):733-44. [PMID:3182877] http://dx.doi.org/10.1016/0021-9290(88)90282-5

3. Alimusaj M, Fradet L, Braatz F, Gerner HJ, Wolf SI. Kinematics and kinetics with an adaptive ankle foot system during stair ambulation of transtibial amputees. Gait Posture. 2009;30(3):356-63. [PMID:19616436] http://dx.doi.org/10.1016/j.gaitpost.2009.06.009

4. Torburn L, Schweiger GP, Perry J, Powers CM. Below-knee amputee gait in stair ambulation. A comparison of stride characteristics using five different prosthetic feet. Clin Orthop Relat Res. 1994;(303):185-92. [PMID:8194232]

5. Yack HJ, Nielsen DH, Shurr DG. Kinetic patterns during stair ascent in patients with transtibial amputations using three different prostheses. J Prosthet Orthot. 1999;11(3):57-62.

6. Medicare. Medicare region C durable medical equipment regional carrier: Supplier update workshop. 1992.

7. Gailey RS, Roach KE, Applegate EB, Cho B, Cunniffe B, Licht S, Maguire M, Nash MS. The amputee mobility predictor: An instrument to assess determinants of the lowerlimb amputee's ability to ambulate. Arch Phys Med Rehabil. 2002;83(5):613-27. [PMID:11994800]

8. Schmalz T, Blumentritt S, Marx B. Biomechanical analysis of stair ambulation in lower limb amputees. Gait Posture. 2007;25(2):267-78. [PMID:16725325] http://dx.doi.org/10.1016/j.gaitpost.2006.04.008

9. Gailey R, Allen K, Castles J, Kucharik J, Roeder M. Review of secondary physical conditions associated with lower-limb amputation and long-term prosthesis use. J Rehabil Res Dev. 2008;45(1):15-29. [PMID:18566923] http://dx.doi.org/10.1682/JRRD.2006.11.0147

10. Morgenroth DC, Gellhorn AC, Suri P. Osteoarthritis in the disabled population: a mechanical perspective. PM R. 2012;4(5 Suppl):S20-27. [PMID:22632698] http://dx.doi.org/10.1016/j.pmrj.2012.01.003
11. Agrawal VR, Gailey RS, O’Toole CO, Gaunaurd IA, editors. Evaluation of the Proprio foot during functional activities: An SEW approach. Proceedings of the National Assembly of the American Orthotics and Prosthetics Association; 2009; Seattle, WA.

12. Agrawal V, Gailey R, O’Toole C, Gaunaurd I, Dowell T. Symmetry in external work (SEW): A novel method of quantifying gait differences between prosthetic feet. Prosthet Orthot Int. 2009;33(2):148-56. [PMID:19367518] http://dx.doi.org/10.1080/03093640902777254

13. Koch M. [Measuring plantar pressure in conventional shoes with the TEKSCAN sensory system]. Biomed Tech (Berl). 1993;38(10):243-48. German. [PMID:8268402] http://dx.doi.org/10.1515/bmte.1993.38.10.243

14. Mueller MJ, Strube MJ. Generalizability of in-shoe peak pressure measures using the F-scan system. Clin Biomech (Bristol, Avon). 1996;11(3):159-64. [PMID:11415614] http://dx.doi.org/10.1016/0268-0033(95)00047-X

15. Stacoff A, Diezi C, Luder G, Stüssi E, Kramers-de Quervain IA. Ground reaction forces on stairs: Effects of stair inclination and age. Gait Posture. 2005;21(1):24-38.

[PMID:15536031]

http://dx.doi.org/10.1016/j.gaitpost.2003.11.003

16. Riener R, Rabuffetti M, Frigo C. Stair ascent and descent at different inclinations. Gait Posture. 2002;15(1):32-44.

[PMID:11809579] http://dx.doi.org/10.1016/S0966-6362(01)00162-X

17. Torburn L, Perry J, Ayyappa E, Shanfield SL. Below-knee amputee gait with dynamic elastic response prosthetic feet: A pilot study. J Rehabil Res Dev. 1990;27(4):369-84. [PMID:2089148] http://dx.doi.org/10.1682/JRRD.1990.10.0369

Submitted for publication June 26, 2012. Accepted in revised form December 4, 2012.

This article and any supplementary material should be cited as follows:

Agrawal V, Gailey RS, Gaunaurd IA, O’Toole C, Finnieston AA. Comparison between microprocessorcontrolled ankle/foot and conventional prosthetic feet during stair negotiation in people with unilateral transtibial amputation. J Rehabil Res Dev. 2013;50(7):941-50. http://dx.doi.org/10.1682/JRRD.2012.05.0093

ResearcherID/ORCID: Robert S. Gailey, PhD, PT: I-34582013; Ignacio A. Gaunaurd, PhD, MSPT: I-3490-2013

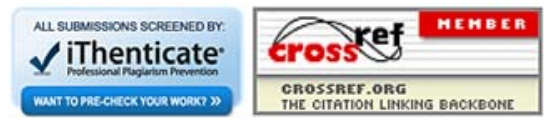

